Time spent on line in school and outside of school Minutes per day spent using the Internet (lower bound on the average)

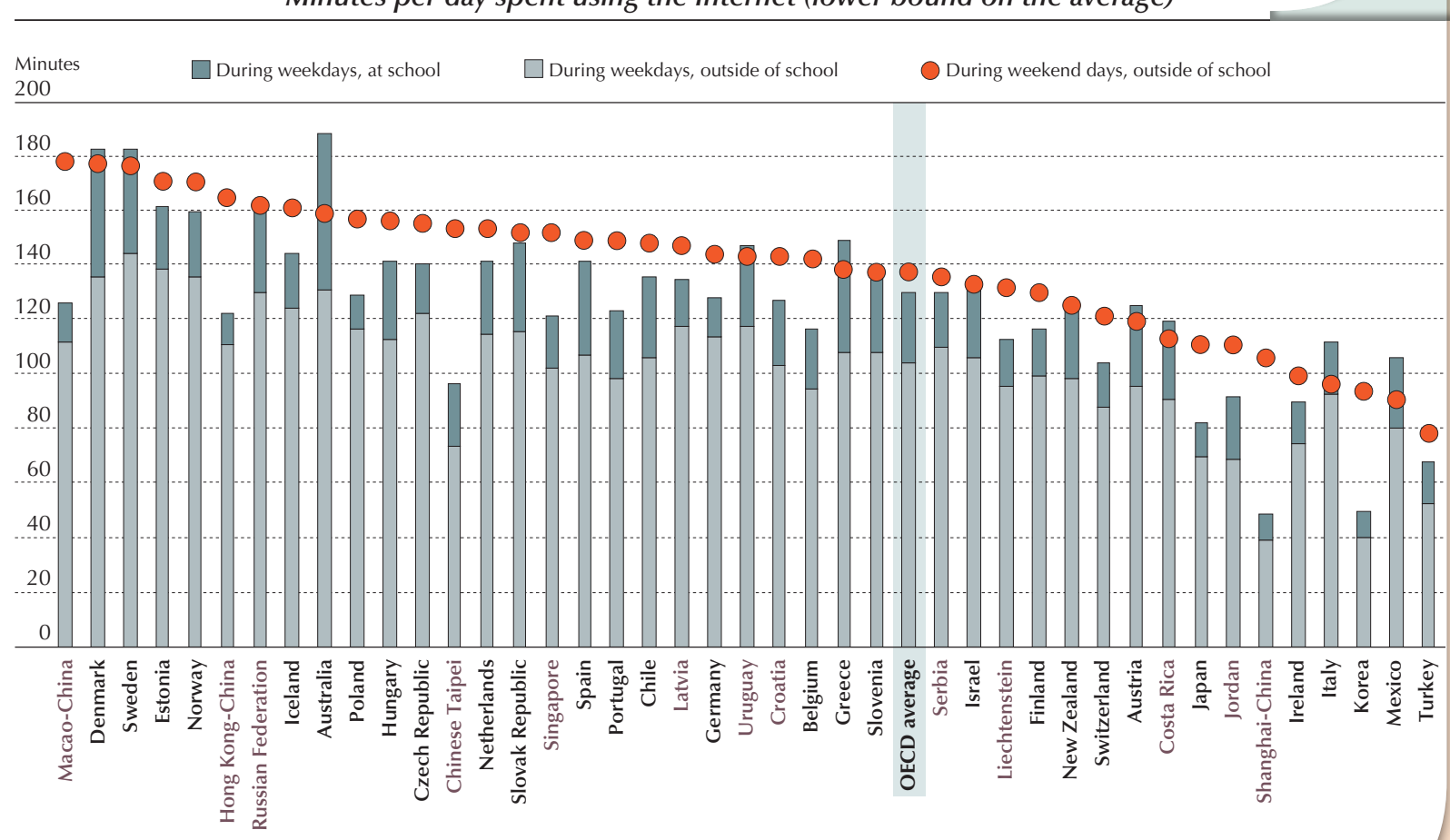

Countries and economies are ranked in descending order of the average time students spend using the Internet during weekend days, outside of school. Source: OECD, PISA 2012 database [Students, Computers and Learning], Tables 1.5a, b and c.

StatLink न्नामा http://dx.doi.org/10.1787/888933252638

What students do on line for leisure outside of school

Percentage of students who reported engaging in each activity every day or almost every day

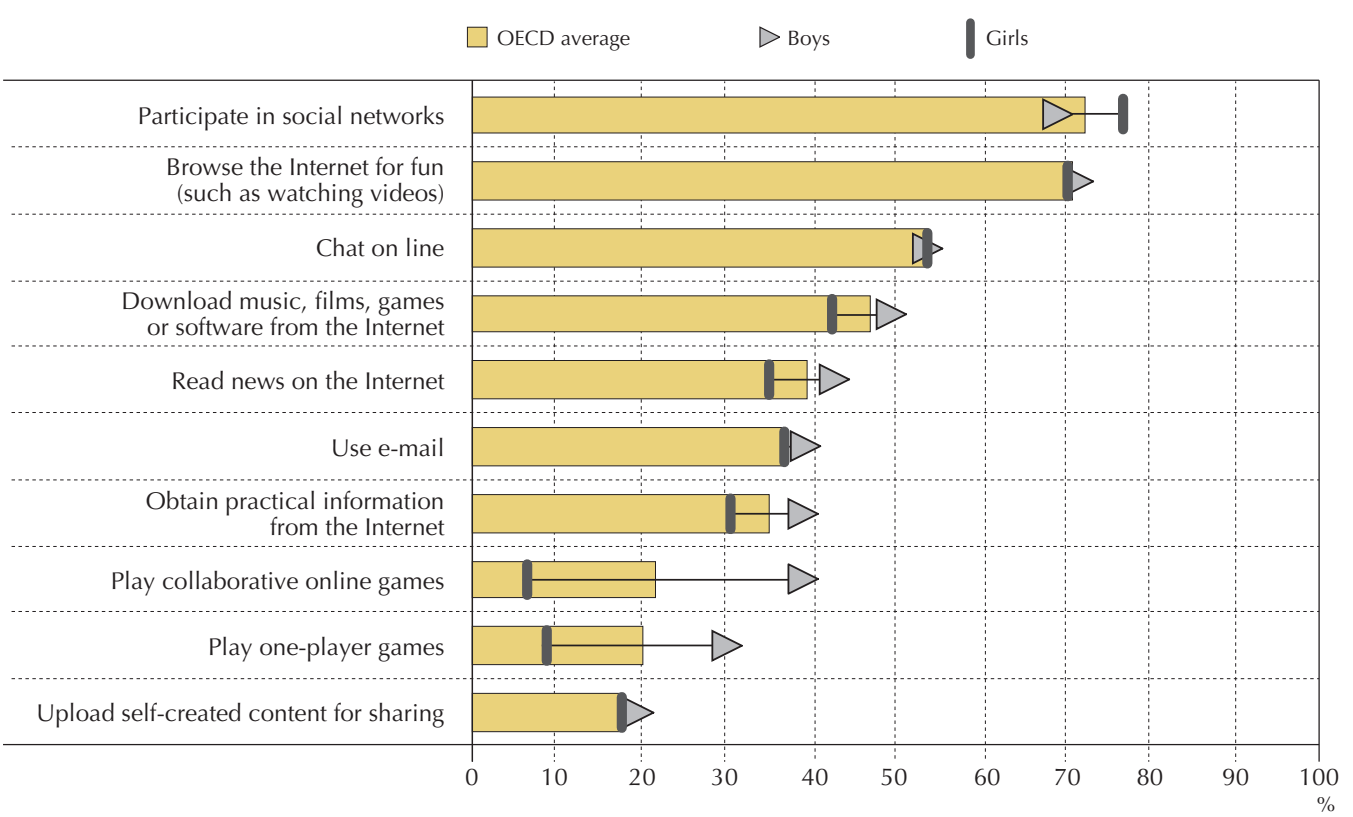

Source: OECD, PISA 2012 database. 
In countries where almost all students, irrespective of their family's socio-economic status, have access to the Internet at home, disadvantaged students often spend at least as much time on line as their more advantaged peers. In nine countries/economies (Belgium, Germany, Hong Kong-China, Iceland, Korea, Norway, ShanghaiChina, Switzerland and Chinese Taipei), students from the bottom 25\% of socio-economic status even spend more time on line than students from the most privileged $25 \%$. At all levels of society, today's children and teenagers grow up in a highly "connected" environment.

... and many don't realise the dangers of being caught in the web.

While children gain access to a host of educational resources and engaging experiences through digital devices and the Internet, concerns are also mounting about the possible harmful consequences of unrestricted Internet use. Children clearly need to be protected from online threats, such as exposure to harmful content or contacts (think pornography or cyberbullying), online fraud or abusive marketing practices, and privacy-related risks, such as identity theft. Many of these risks existed well before the Internet, but measures to protect children from the corresponding offline threats (such as physical barriers, age-related norms that prevent access to certain spaces, and adult supervision) are difficult to migrate and enforce in a virtual space that is inherently open.

Research has also shown that extended screen time in itself may have negative consequences, e.g. on adolescents' sleep, physical activity and social well-being. PISA data confirm and extend these findings.

Student well-being and time spent on line

Percentage of students who agreed or strongly agreed with the statement, "I feel lonely at school", by the amount of time spent on the Internet outside of school during weekdays

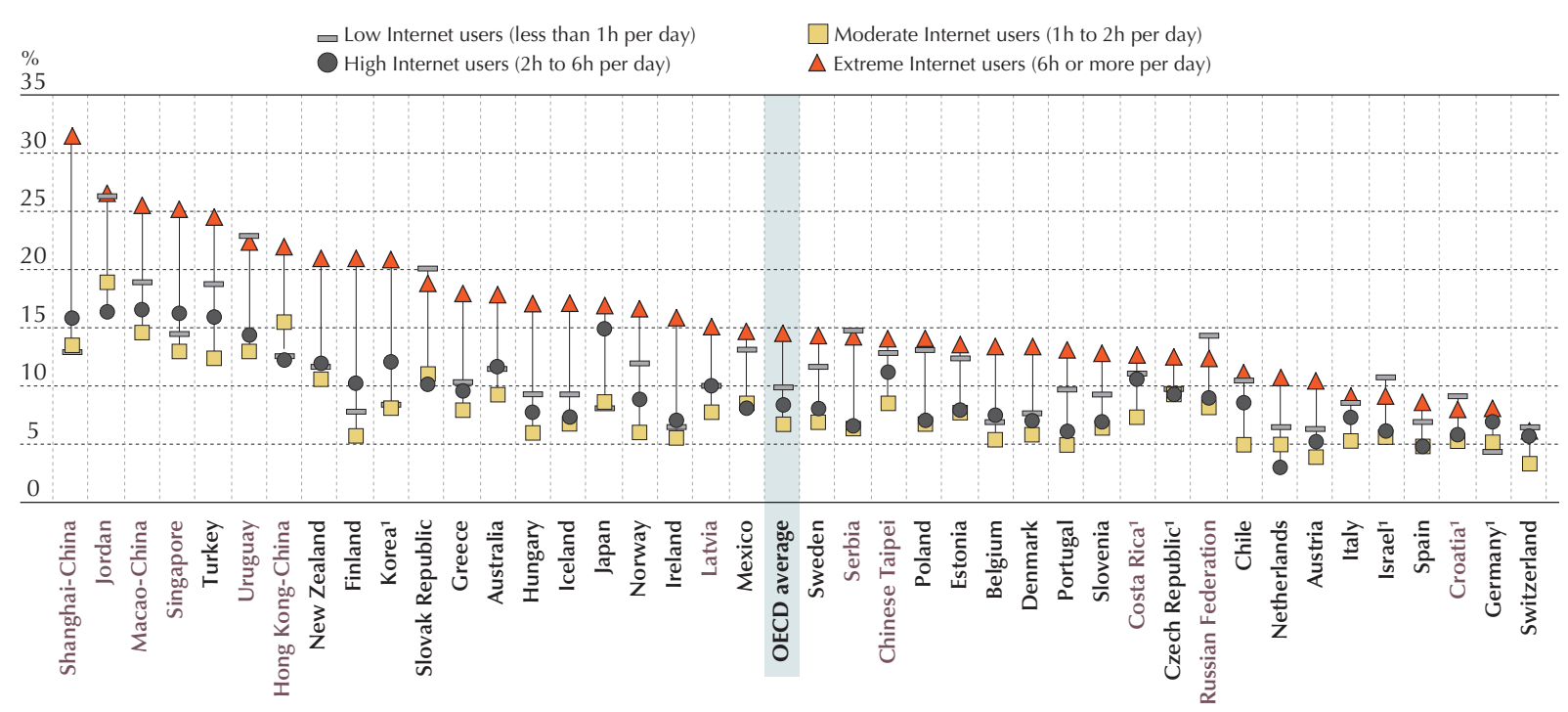

1. The difference between moderate and extreme Internet users is not statistically significant.

Countries and economies are ranked in descending order of the percentage of extreme Internet users who express feelings of loneliness at school. Source: OECD, PISA 2012 database [Students, Computers and Learning], Table 1.8.

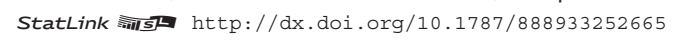


For instance, students' answers to questions about their sense of belonging at school show a troubling relationship with the time they spend on line outside of school. Results clearly indicate lower levels of well-being among extreme Internet users, who spend six or more hours per day on line during weekdays. These students are twice as likely as moderate Internet users (those who spend between one and two hours per day on line) to report that they feel lonely at school (14\% compared to $7 \%$ ). Conversely, students who are well-integrated at school are less likely to spend more than six hours per day on line.

PISA data also show that extreme Internet users are particularly at risk of being less engaged with school. For instance, while $32 \%$ of students who spend less than one hour per day on line during weekdays arrived late for school in the two weeks prior to the PISA test, $45 \%$ of students who spend more than six hours per day on line arrived late.

And extreme Internet users also score below their peers in the PISA assessment of mathematics, on average.

While these findings cannot prove cause and effect, they suggest that well-being at school is related to the electronic media diet outside of school. The fact that learning outcomes are negatively related to intensive surfing on the Internet shows that finding the "right" use for technology is not just an issue for students' leisure time, but also a growing concern for school systems. Parents, schools and health professionals can work together to monitor and plan children's use of new media.

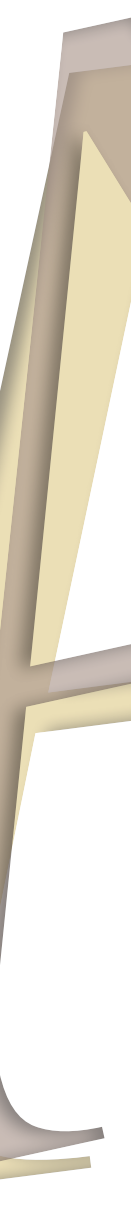

The bottom line: A concerted effort by schools, parents and society can educate students as critical consumers of Internet services and electronic media, helping them to make informed choices and avoid harmful behaviours. Schools can raise awareness in families about the risks that children face on line and how to avoid them. And parents must help children to balance leisure uses of ICT with time for other recreational activities that do not involve screens, such as sports and, equally important, sleep.

\section{For more information}

Contact Francesco Avvisati (francesco.avvisati@oecd.org)

See OECD (2015), Students, Computers and Learning: Making the Connection, PISA, OECD Publishing, Paris, DOI: http://dx.doi.org/10.1787/9789264239555-en.

\section{Visit}

www.pisa.oecd.org

www.oecd.org/pisa/infocus

Coming next month

Education Indicators in Focus

Who are the low performers?

Teaching in Focus

Photo credits: $\odot$ khoa vu/Flickr/Getty Images $@$ Shutterstock/Kzenon $@$ Simon Jarratt/Corbis

This paper is published under the responsibility of the Secretary-General of the OECD. The opinions expressed and the arguments employed herein do not necessarily reflect the official views of OECD member countries.

This document and any map included herein are without prejudice to the status of or sovereignty over any territory, to the delimitation of international frontiers and boundaries and to the name of any territory, city or area.

The statistical data for Israel are supplied by and under the responsibility of the relevant Israeli authorities. The use of such data by the OECD is without prejudice to the status of the Golan Heights, East Jerusalem and Israeli settlements in the West Bank under the terms of international law. 